\title{
Применение принципа контроля \\ государством, принимающим финансовые услуги, в праве ЕС
}

Лукинская М.П.

В статье рассматривается место и роль в финансовом праве Европейского союза принципа контроля принимающим государством деятельности кредитно-финансовых учреждений в ЕС, а также истоки и юридическая основа данного принципа. Большое внимание уделено анализу Директивы 2004/39/EC от 21 апреля 2004 г. о рынках финансовых инструментов с позиции основных полномочий принимающего государства. Раскрываются такие ключевые понятия, как принимающее государство, государство регистрации и профессиональные клиенты, а также рассматриваются особенности, виды и содержание контролирующих норм принимающего государства для компаний, оказывающих финансовые услуги. Исследуется проблематика разграничения и дублирования контролирующих полномочий между государством регистрации и принимающим государством. Характеризуется роль Суда ЕС в утверждении принципа контроля принимающим государством в европейском финансовом праве. Разбирается практика Суда ЕС по ключевым делам, оказавшим влияние на формирование и развитие концепции контроля принимающим государством. Завершает статью анализ текущей стратегии контроля за перемещением капитала в ЕС.

Ключевые слова: принимающее государство; государство регистрации; финансовые услуги; профессиональный клиент; пруденциальный контроль.

Принцип контроля государством, принимающим услуги кредитно-финансовых учреждений в Европейском союзе, закреплен положениями Директивы 2004/39/ЕС о рынках финансовых инструментов ${ }^{1}$ (далее Директива), принятой Советом Европейского союза 21 апреля

\footnotetext{
* Лукинская Мария Петровна - аспирант кафедры Европейского права МГИМО (У) МИД РФ. mkushka@msn.com.

1 Директива 2004/39/EC от 21 апреля 2004 г. о рынках финансовых инструментов, вносящая изменения в Директивы 85/611/ЕЭС, 93/6/ЕЭС, 2000/12/ЕС и отменяющая Директиву 93/22/EC // OJ L 145, 30.4.2004, pp. 1-44.
} 
2004 года. Согласно Директиве принимающим государством является государство-член ЕС, в котором кредитно-финансовое учреждение предоставляет услуги и/или осуществляет деятельность через головной офис либо посредством учреждения филиала.

Для защиты прав инвесторов и поддержания стабильности финансовой системы Европейского союза, все лица, оказывающие инвестиционные услуги и/или ведущие инвестиционную деятельность, за исключением лиц указанных в Директиве, обязаны получить разрешение от компетентного органа на право оказывать такие услуги и/ или вести такую деятельность. При этом основные полномочия по осуществлению надзора за оказанием инвестиционных услуг или ведению инвестиционной деятельностью лицами на основании полученного разрешения, принадлежат государству регистращии, то есть государству - члену EC, в котором находится головной офис (в случае если инвестиционная компания является физическим лицом) либо зарегистрированный офис (если инвестиционная компания - юридическое лицо) такого лица.

Однако Директива также обозначает и сферы вмешательства принимающего государства в экономическую деятельность инвестиционных компаний ${ }^{2}$ Так принимающее государство обладает следующими полномочиями:

(1) информационные полномочия сводятся к праву компетентного органа принимающего государства потребовать от инвестиционных компаний, имеющих филиалы на территории такого принимающего государства, для целей статистического учета периодически ему докладывать о деятельности таких филиалов;

(2) право потребовать от филиалов инвестиционных компаний предоставления информации необходимой для контроля за выполнением такими филиалами стандартов, установленных принимающим государством;

(3) право принимать необходимые меры для защиты инвесторов, включая право лишить инвестиционную компанию возможности совершения сделок на территории принимающего государства, в случае если компетентный орган такого принимающего государства небезосновательно полагает, что инвестиционная компания или филиал, ведущие деятельность на его территории, нарушают обязательства,

2 Директива 2004/39/ЕС от 21 апреля 2004 г. о рынках финансовых инструментов // OJ L 145, 30.4.2004, статьи 61,62. 
предусмотренные Директивой. При этом компетентный орган принимающего государства обязан:

(а) уведомить компетентный орган государства регистрации о фактах нарушения, и в случае, если меры, принятые государством регистрации, не привели к прекращению неправомерных действий инвестиционной компании или филиала, компетентный орган принимающего государства вправе принять указанные выше меры, предварительно известив об этом компетентный орган государства регистрации;

(б) при наличии полномочий компетентного органа принимающего государства, потребовать непосредственно от инвестиционной компании незамедлительного исправления нарушения. Если же инвестиционная компания не устранит нарушения, компетентный орган принимающего государства вправе принять все необходимые меры для прекращения таких нарушений. В случае если такие меры не остановят неправомерных действий инвестиционной компании, компетентный орган принимающего государства вправе принять меры, указанные в третьем пункте, предварительно известив об этом компетентный орган государство регистрации;

(4) право лишить регулируемый рынок или многостороннюю торговую систему возможности предоставлять свои системы для пользования участникам, в случае если компетентный орган такого принимающего государства обоснованно полагает, что регулируемый рынок или многосторонняя торговая система нарушают обязанности, предусмотренные Директивой. При этом компетентный орган принимающего государства предварительно обязан уведомить компетентный орган государства регистрации о фактах нарушения, и только в случае, если меры, принятые государством регистрации, не способствуют прекращению неправомерных действий регулируемого рынка или многосторонней торговой системы, компетентный орган принимающего государства вправе принять указанные выше меры, предварительно известив об этом компетентный орган государства происхождения.

Следует отметить, что данный порядок, особенно консультации с государством регистрации до момента принятия мер органами принимающего государства, создает определенные сложности. Так как принимающее государство должно обладать рядом регулирующих и надзорных полномочий применительно к инвестиционным компаниям, действующим на его территории, то необходимо обеспечить принимающему государству возможность надлежащего применения своих 
принудительных норм, с соответствующим уведомлением государства регистрации. Современные финансовые рынки очень сложны и динамичны. Поэтому контролирующие органы должны не только понимать общие принципы функционирования рынка, но осознавать то, что даже незначительная задержка с введением требуемых мер может подвергнуть риску финансовое состояние инвесторов и повредить стабильности рынка.

В целях обеспечения лучшего надзора за деятельностью инвестиционных компаний между контролирующими органами, ликвидирующими инстанциями, аудиторами, правоохранительными и иными регулирующими органами принимающего государства и государства регистрации предусмотрен обмен информацией и сотрудничество. Европейская комиссия со своей стороны обязала штатных аудиторов и органы, занимающиеся процедурами ликвидации и банкротства, информировать компетентные органы государства регистрации и принимающего государства о любых несоответствиях в деятельности инвестиционных и кредитно-финансовых предприятий.

Анализируя Директиву можно прийти к выводу, что основной целью данного акта является обеспечение свободы осуществления экономической деятельности, а также свободы предоставления услуг. В связи с этим принимающие государства должны обеспечивать отсутствие препятствий для инвестиционных компаний, оказывающих инвестиционные услуги либо ведущих инвестиционную деятельность на основании разрешения, выданного государством происхождения, при условии, что такие действия инвестиционной компании не противоречат нормативно-правовым актам принимающего государства, обеспечивающим концепцию всеобщего блага.

Кроме того полномочия принимающего государства закреплены в прецедентном праве Суда ЕС. Так, в деле 120/78 Cassis de Dijon ${ }^{3}$ Суд пытался контролировать полномочия принимающего (импортирующего) государства в рамках статьи 28 Договора об учреждении ЕЭС, устанавливая два регулирующих принципа. Прежде всего, Суд признал отклонение от свободы перемещения товаров в степени, необходимой для того, чтобы меры, предпринимаемые импортирующим государством, удовлетворяли обязательным требованиям. Кроме того, Суд постановил, что односторонние требования, применяемые в соответствии

${ }^{3}$ Суд Европейских Сообществ. Избранные решения / Отв. ред. докт. юрид. наук, проф. Л.М. Энтин. - М.: Издательство НОРМА, 2001. - С. 120-131. 
с нормами импортирующего государства-члена ЕС, не отвечают положениям статьи 28 Договора об учреждении ЕЭС в случае, если импортируемые товары законным образом произведены и продаются в государстве регистрации, являющимся членом Сообщества.

Что касается услуг, в решении по делу C-76/90 Säger ${ }^{4}$ Суд прояснил, что статья 59 Договора о ЕЭС применяется в отношении норм принимающего государства и требует отмены любых ограничений, если такие ограничения способны препятствовать деятельности поставщика услуг, учрежденного в другом государстве-члене ЕС. Однако Суд постановил, что принимающее государство вправе применять меры направленные на защиту государственных интересов.

В решении по делу 205/84 Commission v Germany ${ }^{5}$ Суд постановил, что возможны случаи, в которых, в силу природы застрахованного риска и стороны, желающей застраховать такой риск, отсутствует необходимость защиты указанной стороны посредством применения обязательных норм принимающего государства. Несомненно, что сфера действия такого постановления выходит за рамки области страхования.

Согласно выводу, к которому Суд ЕС пришел в деле С-410/96 $A m b r y^{6}$, степень наделения принимающего государства полномочиями на принятие мер, ограничивающих доступ на рынок для финансовых компаний, учрежденных в государстве - члене ЕС, может повлечь ряд сложностей. Так, чем ниже степень гармонизации надзорных норм, тем большими полномочиями для использования национальных норм в интересах всеобщего блага обладает принимающее государство. Чем шире полномочия принимающего государства, тем более явным является отсутствие выгоды для инвестиционных фирм, планирующих начать финансовую деятельность за пределами государства регистрации, тем ниже конкуренция и нагрузка на национальную инвестиционную компанию принимающего государства.

Как указано выше в статье, ответственность за выдачу разрешений на оказание инвестиционных услуг или осуществление деятельности инвестиционным фирмам несут компетентные органы государства регистрации. Здесь возникает вопрос: возможно ли контролирующим органам принимающего государства проводить проверки кредитнофинансового учреждения, планирующего осуществлять деятельность

\footnotetext{
${ }^{4}$ Case C-76/90 Manfred Säger v Dennemeyer \& Co. Ltd. [1991] ECR 1-4421.

${ }^{5}$ Case 205/84 Commission v Germany [1986] ECR 3755.

${ }^{6}$ Case C-410/96 Ambry [1998] ECR I-7875, paragraphs 25-39.
} 
на территории такого принимающего государства, на предмет соответствия компании условиям, на основании выполнения которых такая компания получила разрешение в государстве регистрации.

В соответствии с положениями Директивы, подобные проверки на предмет соответствия должны осуществляться исключительно государством регистрации. Таким образом, подразумевается, что если разрешение на осуществление деятельности на трансграничной основе выдается кредитно-финансовому учреждению уполномоченными органами государства регистрации, принимающее государство не должно оспаривать факт предоставления такого разрешения. Данное утверждение также закреплено в решении Суда ЕC по делу C-11/95 Commission v Belgium ${ }^{7}$, где Суд постановил, что принимающее государство не имело права оспаривать применение права государства-отправителя в отношении телевизионного вещания ${ }^{8}$.

Однако если принимающее государство небезосновательно полагает, что финансовая компания, получившая разрешение, не соответствует требованиям условий для выдачи такого разрешения, принимающее государство обязано найти иные способы удовлетворения своих требований. Так, оно может потребовать от Европейской комиссии возбудить дело против государства регистрации за невыполнение им своих обязательств, предусмотренных Директивой. Однако ни при каких обстоятельствах принимающему государству не разрешается самостоятельно возбуждать дело и контролировать соответствие кредитно-финансового учреждения требованиям, предусмотренным Директивой, так как это является нарушением гарантируемых учредительными Договорами свобод учреждения и осуществления экономической деятельности, а также свободы предоставления услуг.

Директива содержит нормы, регулирующие осуществление экономической деятельности, которым обязаны следовать финансовые компании, а также нормы применимые к пруденциальным мерам, которые инвестиционные компании должны принимать для максимального соответствия условиям деятельности, предусмотренным положениями Директивы. Различие между нормами пруденциально-структурного характера и нормами осуществления деятельности велико, так как

\footnotetext{
${ }^{7}$ Case C-11/95 Commission v Belgium [1996] ECR I-4118, paragraph 34.

${ }^{8}$ Council Directive 89/552/EEC of October 1989 on the condition of certain provisions laid down by Law, Regulation or Administrative Action in member States concerning the pursuit of television broadcasting activities //OJ L 298/23, 17 October, 1989.
} 
указанные нормы применяются в отношении сопутствующих инвестиционных услуг ${ }^{9}$. Пруденциальные нормы распространяются на выдачу разрешения и эффективный надзор за кредитно-финансовыми учреждениями, торгующими ценными бумагами. Они контролируют условия получения исходного и действующего в течение определенного срока разрешения на публичное предложение покупки ценных бумаг, либо торговли ценными бумагами от лица инвесторов. Напротив, нормы осуществления деятельности контролируют сделки между эмитентами, дилерами и инвесторами, отвечают за применение норм, регулирующих осуществление экономической деятельности между финансовыми предприятиями и их клиентами.

На практике возможно возникновение дублирования полномочий между пруденциальными нормами и нормами осуществления деятельности. Например, с позиции защиты прав потребителей, структура и внутренние механизмы контроля финансовых компаний напрямую связаны с характером сделки. В рамках концепции всеобщего блага, компетентные органы принимающего государства могут быть заинтересованы в мерах осуществления надзора за пруденциальным контролем государством регистрации. При этом пруденциальные нормы, применяемые в отношении личных сделок сотрудников компании, могут противоречить нормам осуществления деятельности, установленным в принимающем государстве и представлять конфликт интересов. В данном контексте показательным является бельгийское право, которое явным образом противоречит принципу контроля государством регистрации, наделяя контролирующий орган принимающего государства (Банковско-финансовая комиссия, Commission Bancaire et Financiere ${ }^{10}$ ) полномочиями проверки деятельности филиалов иностранных инвестиционных компаний на предмет соблюдения ими бельгийских законов, а также соответствия принципам законности административной и бухгалтерской структуры и адекватности внутренних мер контроля.

Кроме того, требование Директивы о необходимости ведения учета государством регистрации сделок, совершенных инвестиционными фирмами, подразумевает, что у принимающего государства не имеется никаких полномочий контроля в данной сфере. Однако представляется, что в круг задач принимающего государства должна входить

9 Директива 2004/39/ЕС от 21 апреля 2004 г. о рынках финансовых инструментов // OJ L 145, 30.4.2004. - Раздел В, приложение I.

${ }^{10}$ URL: http://www.cbfa.be/eng/index.asp. 
возможность контроля своих собственных рынков и отслеживание осуществляемых на них сделок в интересах защиты прав потребителей.

Для компетентного органа принимающего государства важно обладать возможностью проведения сквозных аудиторских проверок по сделкам, предпринятым определенной финансовой компанией в отношении ценных бумаг, либо на регулируемом рынке в пределах своей юрисдикции. Такие надзорные полномочия могли бы предотвращать возможные нарушения норм кредитно-финансовыми учреждениями, не только установленных Директивой, но и национальных норм принимающего государства. Поэтому для компетентных органов принимающего государства очень важно обладать полномочиями на введение определенных правил учета и контроля в целях мониторинга исполнения национальных норм.

В Директиве учитывается проблема противоречия норм и конфликта интересов в случае учреждения филиала инвестиционной фирмы. Принимающее государство вправе принимать нормы во избежание конфликтов интересов, либо в целях обеспечения справедливого их разрешения. В то же время, государство регистрации обладает полномочиями требовать от инвестиционной компании выполнения определенных структурных и организационных условий в целях сведения к минимуму риска причинения ущерба клиенту в случае конфликта интересов.

Национальные нормы контроля за осуществлением деятельности кредитно-финансовых учреждений значительно отличаются в государствах-членах ЕС. Например, голландское право рассматривает нормы осуществления финансовой деятельности как юридически обязательные для инвестиционных компаний, учрежденных в соответствии с голландским правом, но не содержит уточнений об их зарубежной деятельности в других государствах-членах. Право Люксембурга идет еще дальше: в нем не только существуют нормы осуществления деятельности для филиалов компаний, учрежденных в Люксембурге, но действие указанных норм также распространяется на иностранные дочерние компании. Следовательно, реализующая свою свободу предоставления услуг финансовая компания не может быть связана только нормами осуществления деятельности государства регистрации, она также может подпадать под действие норм принимающего государства. Поэтому несогласованные нормы осуществления деятельности являют собой неизбежное, зачастую труднопреодолимое препятствие 
для формирования на едином рынке свободы перемещения инвестиций и в целом свободы передвижения финансовых услуг.

Риск дублирования норм также способен оказать негативное влияние на защиту прав потребителей. Так как перед каждым государством-членом ЕС стоит задача регулирования сделок и введения норм осуществления деятельности в пределах своей территории, уровень защиты прав потребителей и контроль исполнения будут отличаться в разных странах ЕС. Можно утверждать, что защита прав потребителей выходит за рамки сформулированных положений директив о финансовых услугах и национальных законов государств-членов о ценных бумагах. Инвесторов больше всего интересует надежность брокеров и надежность своих инвестиций. Поэтому главным вопросом является сама сделка, регулируемая согласно нормам осуществления деятельности и контролируемая компетентным органом принимающего государства. Различий в стандартах защиты прав инвесторов едва ли можно избежать, пока нормы осуществления деятельности не будут полностью гармонизированы в пределах ЕС.

Европейская комиссия считает, что нормы осуществления деятельности, установленные государством регистрации, обеспечивают достаточную и эквивалентную защиту интересов профессиональных инвесторов ${ }^{11}$.

Директива раскрывает понятие «профессиональный клиент». ${ }^{12}$ Так, профессиональным является лицо, имеющее необходимый опыт и знания для принятия независимых инвестиционных решений и оценки возможных рисков. Также профессиональные клиенты должны отвечать ряду требований:

(а) наличие разрешения на ведение финансовой деятельности; профессиональными клиентами являются

(б) крупные организации, выполняющие два из следующих требований: (1) валюта баланса - 20000000 евро; (2) чистый оборот 40000000 евро; (3) собственный капитал - 2000000 евро;

(в) центральные банки, национальные и региональные правительства, международные и наднациональные организации, органы, управляющие национальным долгом;

${ }^{11}$ European Commission, Communication on the Application of Conduct of Business Rules under Article 11 of the Investment Services Directive 93/22/EEC. - 16 November 2000.- p. 18. 12 Директива 2004/39/ЕС от 21 апреля 2004 г. о рынках финансовых инструментов // OJ L 145, 30.4.2004. - приложение II. 
(г) инвесторы, чья основная деятельность состоит из инвестирования в финансовые инструменты.

Как отмечалось выше, в целом нормы осуществления деятельности регулируют сделки по финансовым продуктам и поставке таких продуктов от финансовой компании клиенту. В этом отношении они тесно связаны с нормами контроля маркетинга таких продуктов, в частности их рекламирования. В то время как выдача разрешения и пруденциальный контроль - требования, входящие в обязанности государства регистрации, Директива подразумевает, что за нормы маркетинга и рекламирования отвечает принимающее государство.

Дублирование или конфликт полномочий может возникать не только между нормами государства регистрации и принимающего государства, но также между третьим государством, не государством - участником ЕС, в котором фактически оказываются инвестиционные услуги или ведется инвестиционная деятельность. В качестве примера можно привести деятельность французского филиала британской инвестиционной компании, выполняющего поручения своих французских клиентов на Афинской бирже деривативов. В соответствии с положениями Директивы, филиал обязан соблюдать национальные нормы принимающего государства,

В отношении инвестиционных услуг, Директива предусматривает, что государства-члены ЕС не должны применять режим наибольшего благоприятствования для филиалов инвестиционных компаний, имеющих юридический адрес за пределами ЕС и осуществляющих там свою деятельность, по сравнению с филиалами инвестиционных компаний, зарегистрированных в государствах - членах ЕС.

На сегодняшний день четко видна разница между рыночными режимами, применяющимися для финансовых компаний, для которых ни одна из стран ЕС не является государством регистрации, а каждое государство - член ЕС играет роль принимающего государства. Это особенно очевидно в сфере перемещения капитала и проведения платежей.

Представляется очевидным, что, применительно к отношениям с третьими странами право ЕС не обладает достаточной юридической базой для отмены ограничений, существующих в соответствии с национальными правовыми режимами государств - членов ЕС. Это касается перемещения капитала в/из третьих стран, в том числе прямого инвестирования, предоставления финансовых услуг или доступа ценных бумаг на рынки капитала. Как представляется, целью рассмотренной 
Директивы и иных принятых финансовых директив является поддержание открытости финансовых рынков для третьих стран. По нашему мнению, для решения этой задачи необходимо способствовать согласованию условий для учреждения филиалов и предоставления услуг на трансграничной основе инвестиционными компаниями третьих стран, по крайней мере, в отношении тех стран, которые признают требования режима взаимного признания.

\section{Библиографический список}

Бирюков М.М. Европейское право до и после Лиссабонского договора. - М.: Научная книга, 2010.

Буренин А.Н. Рынок ценных бумаг и производных финансовых инструментов : учеб. пособие / А.Н. Буренин; Научно-техн. о-во им. академика С.И. Вавилова. - 2-е изд., перераб. и доп. - М., 2002. - 352 с. (Теория и практика финансового рынка). - ISBN 5-902189-01-2.

Вишневский А.А. Банковское право Европейского Союза: учеб. пособие. - М.: Статут, 2000. - 388 с. - ISBN 5-8354-0048-9.

Европейское право. Право Европейского Союза и правовое обеспечение защиты прав человека: учебник / рук. авт. кол. и отв. ред. Л.М. Энтин. - 3-е изд., пересмотр, и доп. - М.: Норма: ИНФРА-М, 2011.

Кузнецов А.В., Четверикова А.С. Восточноевропейские страны ЕС: куда идут их инвестиции // Современная Европа. - 2007. - № 4.

Романова Т. А. Иностранные инвестиции в становлении ЕС как актора на мировой арене // Вестник Санкт-Петербургского государственного университета. - 2002. - Серия 6. - Выпуск 2.

Суд Европейских Сообществ. Избранные решения / Отв. ред. докт. юрид. наук, проф. Л.М. Энтин. - М.: Издательство НОРМА, 2001.

Титов К.В. Региональная экономическая интеграция в ЕС // Мировая экономика и международные отношения. -2000 . - № 10 .

Фархутдинов И.З. Международное инвестиционное право: теория и практика применения. - М.: Волтерс Клувер, 2005.

Финансовое право: учебник для вузов / под ред. Е.Ю. Грачевой, Г.П. Толстопятенко - М.: ПРОСПЕКТ, 2006. -532 c. - ISBN 5-98032-015-6.

Шеленкова Н.Б. Европейское финансовое право. В 3 т. Т. 1: Правовые основы европейской интеграции. Интеграционное регулирование рынка ценных бумаг. - М.: Добросвет, 2003. - 338 с. - ISBN 5-89737-093-2.

Шеленкова Н. Б. Единый европейский фондовый рынок: вопросы регулирования // Рынок ценных бумаг. - 2003. - № 2. 
Шумилов В.М. Международное финансовое право: учебник / Всерос. академия внешней торговли. - М.: Международные отношения, 2005. - 431 с. - ISBN 5-7133-1249-6.

Berry E., European Union Law - Oxford: Oxford University Press, 2007.

Chalmers, D., and Szyszczak, E., European Union Law. Volume II. Towards a European Policy? - Ashgate: Aldershot, 1998.

Dassesse, M. EC Banking Law. - London, Lloyd's Press, 2nd ed., 1994.

Goodhart, C., Financial Regulation: Why, How and Where Now? London: Routledge, 1998.

Gretschmann, K., The Subsidiary Principle: Who is do what in an Integrated Europe? - Maastricht, 1991.

Lee, R., What is an Exchnage? The Automation, Management and regulation of Financial Markets. - Oxford: Oxford University Press, 1998.

Majone, G., Regulating Europe. - London: Routledge, 1996.

Schmidtchen, D. and Cooter, R., Constitutional Law and Economics of the European Union. - Cheltenham: Edward Elgar, 1997.

Wisbey, G., The Challenge of Technology - Regulation of Electronic Financial Markets. - Cambridge, 2000. 


\section{Application of the Host Member State Control Principal under the Law of the European Union (Summary)}

\section{Maryia P. Lukinskaya*}

The article reviews place and role in the finance law of the European Union of the host member state control principle related to operations of credit and financial institutions in EU, as well as it discovers sources and legal grounds for such principle. The emphasis is given by the author to the analysis of the Directive in relation to the main powers of the host member state. The article examines specifics of the host member state, the home country and the professional client concepts. Additionally types, varieties and content of host member state control regulations for companies rendering financial services are being observed. The author hereby addresses range of problems arising out of absence of distinct separation and duplication of control powers between the home and the host EU countries. The article characterizes the role of the Court of Justice of the European Union in affirmation of the host member state control principle in the European finance law. Therewith the article reviews the case-law of the Court of Justice of the European Union which has great impact on formation and development of the host member state control concept. The article is being finalized by analyses of the current control strategy over capital movement in the European Union.

Keywords: host member state; home country; financial services; professional client; prudential control.

\footnotetext{
* Maryia P. Lukinskaya - post-graduate student of the Chair of European Law, MGIMOUniversity MFA Russia.mkushka@msn.com.
} 